\title{
A HOMOFOBIA EM DISCURSO: DIREITOS HUMANOS EM CIRCULAÇÃO
}

\author{
Gustavo Grandini Bastos* \\ Universidade de São Paulo \\ Faculdade de Filosofia, Ciências e Letras de Ribeirão Preto \\ Ribeirão Preto, SP, Brasil \\ Dantielli Assumpção Garcia ${ }^{* *}$ \\ Universidade Estadual do Oeste do Paraná \\ Cascavel, PR, Brasil \\ Lucília Maria Abrahão e Sousa ${ }^{* * *}$ \\ Universidade de São Paulo \\ Faculdade de Filosofia, Ciências e Letras de Ribeirão Preto \\ Ribeirão Preto, SP, Brasil
}

\begin{abstract}
Resumo: Ancorado no aporte teórico da Análise do Discurso de linha francesa, este artigo tem por objetivo refletir acerca da constituição de sentidos sobre o tema homofobia na página do Facebook da Secretaria de Direitos Humanos da Presidência da República (SDH/PR) Direitos Humanos Brasil de janeiro de 2013 a janeiro de 2015, destacando as noções de ideologia e memória discursiva no trabalho de análise. A análise enfoca a compreensão sobre os efeitos produzidos na inscrição de dizeres acerca da homofobia divulgados nessa página eletrônica oficial do governo, e como o Estado adota determinada posição ao inscrever sentidos acerca de um assunto.
\end{abstract}

Palavras-Chave: Análise do Discurso. Facebook. Direitos Humanos. Homofobia.

\footnotetext{
* Doutorando em Psicologia no Programa de Pós-graduação em Psicologia. Bolsista CAPES. E-mail: guggrandini@gmail.com.

** Pós-Doutoranda na Universidade Estadual do Oeste do Paraná (UNIOESTE). Bolsista CAPES. PósDoutora pela Faculdade de Filosofia, Ciências e Letras de Ribeirão Preto (FFCLRP) da Universidade de São Paulo (USP). Doutora em Estudos Linguísticos pela Universidade Estadual Paulista Júlio de Mesquita Filho (UNESP). E-mail: dantielligarcia@gmail.com.

*** Livre-Docente em Ciências da Informação e da Documentação. Profa. do Curso de Graduação em Ciências da Informação e da Documentação e do Programa de Pós-Graduação em Psicologia - Faculdade de Filosofia, Ciências e Letras de Ribeirão Preto (FFCLRP/USP). Professora colaboradora do Programa de Pós-Graduação em Ciência, Tecnologia e Sociedade da Universidade Federal de São Carlos (UFSCar). Email: luciliamsr@ffclrp.usp.br.
} 
Neste trabalho, filiados à perspectiva teórico-metodológica da Análise do Discurso de linha francesa (doravante AD), atrelada aos pressupostos estabelecidos por Michel Pêcheux, buscamos analisar alguns posts referentes a discursos que abordam a homofobia ${ }^{1}$ na página oficial da Secretaria de Direitos Humanos da Presidência da República (SDH/PR) "Direitos Humanos Brasil"2 no Facebook ${ }^{3}$.

Nosso interesse está em observar o modo como postagens referentes ao preconceito contra a população de Lésbicas, Gays, Bissexuais, Travestis e Transexuais (LGBT) são apresentados em uma página oficial do governo federal brasileiro na rede eletrônica, analisando como esses discursos são inscritos, circulam e são difundidos nas condições de produção da atualidade. Na organização do trabalho, apresentamos considerações sobre: a) a Secretaria de Direitos Humanos da Presidência da República (SDH/PR); b) a noção de homofobia; c) a página da SDH/PR no Facebook, o corpus selecionado para nossa análise e a discussão no campo da $\mathrm{AD}$, trabalhando com reflexões acerca das noções de ideologia e memória discursiva (PÊCHEUX, 1997a, 1997b; ORLANDI, 2007), levando em conta os aspectos discursivos no que diz respeito ao tecnológico.

\section{A HOMOFOBIA E A SECRETARIA DE DIREITOS HUMANOS DA PRESIDÊNCIA DA REPÚBLICA (SDH/PR)}

Nesta parte de nosso texto, discorreremos sobre a Secretaria de Direitos Humanos da Presidência da República ( $\mathrm{SDH} / \mathrm{PR}$ ) e sua relação com os direitos humanos da população LGBT. Foi no ano de 2003 que a SDH/PR adquiriu a condição de um Ministério Federal, pertencendo anteriormente ao Ministério da Justiça desde sua criação no ano de 1977. Os interesses da SDH/PR envolvem o trabalho com políticas relacionadas à defesa e à promoção dos Direitos Humanos no Brasil (BRASIL, 2015).

A noção de Direitos Humanos é compreendida como os direitos pelos quais todos estão resguardados desde o nascimento, cabendo ao Estado assegurar o respeito e a segurança, por meio de acordos, convenções, leis e tratados nacionais e internacionais. Inúmeros documentos existem para assegurar a defesa e a realização das práticas de proteção a tais direitos, como por exemplo, a Declaração Universal dos Direitos Humanos e a Constituição Federal do Brasil de 1988, na qual são destacados os princípios constitucionais visando assegurar a proteção do Estado aos Direitos Humanos de todos os brasileiros (BRASIL, 2015).

\footnotetext{
${ }^{1}$ Destacamos que a noção de homofobia é a mais recorrente para tratar do preconceito frente aos diferentes grupos de sujeitos identificados como atingidos pelo ódio contra a comunidade LGBT; no entanto, conforme alerta Mello, Brito e Maroja (2012), é importante ressaltar que tem sido usual a busca pelo uso de nomeações específicas para destacar a intolerância e o ódio frente a grupos específicos, como as denominações "transfobia", "bifobia" e "lesbofobia". Pudemos observar essas inscrições em um dos materiais que compõe nosso corpus (Figura 3). Destacamos que optamos pelo uso da noção de homofobia para abordar a aversão aos sujeitos que estão inscritos como relacionados à comunidade LGBT, não apenas a um grupo de sujeitos, no caso, os gays.

${ }^{2}$ Disponível em: <https://www.facebook.com/direitoshumanosbrasil?fref=ts>. Acesso em: 28 ago. 2015.

${ }^{3}$ É uma rede social fundada em 2004 e fundada por Mark Zuckerberg, Eduardo Saverin, Dustin Moskovitz e Chris Hughes.
} 
Os Direitos Humanos são universais, assegurando o tratamento equivalente a todas as pessoas; indivisíveis, já que os direitos são reafirmados de maneira conjunta e contínua, mesmo que tenham sido elaborados em momentos distintos; interdependentes, já que a efetivação deve ser completa para que haja o respeito à dignidade humana de todos (BRASIL, 2015). Entre as ações que competem à $\mathrm{SDH} / \mathrm{PR}^{4}$, segundo o Decreto $\mathrm{n}$. 8.162/2013 (BRASIL, 2013), apontamos (grifos nossos):

[...] formulação de políticas e diretrizes voltadas à promoção dos direitos da cidadania, da criança, do adolescente, do idoso e das minorias.

\section{Articular iniciativas e apoiar projetos voltados para a proteção e promoção dos direitos} humanos em âmbito nacional.

\section{Exercer as funções de ouvidoria nacional de direitos humanos, da criança, do adolescente, da pessoa idosa e das minorias.}

A defesa da população LGBT ganha destaque na SDH/PR, sendo uma das áreas de atuação desse órgão público federal, o qual visa a proteger e promover políticas públicas destinadas a essa comunidade. A noção de "minorias", na qual os LGBT estão inscritos, destaca a importância desse assunto nas pautas da SDH/PR. Entendemos que ser parte de "minorias", como no caso da população LGBT, significa estar inscrito em relações de pertencimento e exclusão. Ser parte dessa "minoria" coloca em jogo a negativa de não ser maioria, de não ser heterossexual, produzindo sentidos em outras posições discursivas e estabelecendo outras relações com as instituições governamentais dentro da estrutura política brasileira. Compreendemos que, como efeitos de sentidos, temos a questão da necessidade de uma postura de proteção a esses sujeitos, resultando em ações por parte do Governo Federal no sentido de resguardar e promover diretrizes que permitam a diminuição do preconceito e assegurem a preservação dos direitos básicos desses sujeitos. Ao inscrever sentidos outros acerca da população LGBT, o Governo Federal produz efeitos na relação dessa população com direitos básicos, na sua relação com o Estado e na forma como quem não é LGBT identifica esses sujeitos, já que diretrizes e regulações variadas acarretam diferenças nas formas como os sujeitos se relacionam com essa população.

Agir no sentido de promover a igualdade e de atuar na "proteção e promoção dos direitos humanos" e "exercer as funções de ouvidoria nacional de direitos humanos" permite-nos pensar o gesto de inscrição do Governo Federal de entender que as relações entre heterossexuais e a população LGBT não são equivalentes, por isso, é importante atuar de várias maneiras (ações informativas, discussões, promoção de políticas públicas, etc.) que possibilitem, de alguma maneira, inscrever sentidos outros sobre e referentes aos sujeitos dessa população, permitindo que haja outra ressignificação desses sujeitos postos como "minorias". A busca por promover essas ações destaca a importância das instâncias governamentais no sentido de impedir a violência contra esse grupo, assumindo seu papel na garantia de assegurar direitos e proteção.

\footnotetext{
${ }^{4}$ Disponível em: <http://www.sdh.gov.br/sobre/acesso-a-informacao/institucional>. Acesso em: 10 ago. 2015.
} 
A iniciativa de adotar uma postura de proteção aos LGBT por parte do Governo Federal brasileiro não é aleatória, visto que, como mostram os dados publicados em 2012 pelo Grupo Gay da Bahia (GGB) (BARROS NETO, 2013), foram assassinados 336 homossexuais, sendo que o GGB entende que a quase totalidade desses crimes têm motivação homofóbica, tendo como principal vítima os gays (56\%). Destacamos que a homossexualidade é punida em 78 países, alguns, inclusive com a pena de morte, como apresentado no relatório publicado pela Associação Internacional de Lésbicas, Gays, Bissexuais, Trans e Intersexos (ILGA) em 2012. Ainda há na atualidade, tanto no Brasil como em outras partes do mundo, discursos que perpetuam o entendimento de que a homossexualidade afronta regras morais e sociais.

Historicamente, o preconceito tem sido observado no Brasil, inclusive na forma com que os gays e a comunidade LGBT, de modo amplo, foram descritos e apresentados, visando reprovar seu comportamento, práticas e formas de ser, sendo identificada como "abominação; crime contra a natureza; pecado nefando; vício dos bugres; abominável pecado de sodomia; velhacaria; descaração; desvio; doença; viadagem; frescura" (MOTT, 2001, p. 41). Soares $(2006,2012)$ compreende que a identificação de um sujeito como gay leva ao apagamento de sentidos que não os relacionados à sua sexualidade, inscrevendo-o e significando-o unicamente a partir dessa sexualidade. Como exemplo, podemos destacar a forma preconceituosa com que os sujeitos-gays foram, de maneira recorrente, representados em programas de televisão do Brasil e a maneira negativa com que o espaço criminal, familiar e político encara(va) esses sujeitos, marcando a homofobia como prática que os afeta(va) ao longo da história.

A homofobia pode ser observada nas piadas, agressões físicas e verbais sofridas nas diferentes situações do dia a dia e na rejeição pela própria família. A atitude homofóbica coloca o outro como estranho, o que não cabe identificação ou proximidade, pois é identificado como anormal. A palavra 'homofobia' começou a circular em dicionários franceses na década de 1990, mas parece que sua origem é bem anterior, aparecendo nos EUA da década de 1970. Borrillo (2010, p. 22) define a homofobia da seguinte maneira:

\footnotetext{
O termo 'homofobia' designa, assim, dois aspectos diferentes da mesma realidade: a dimensão pessoal, de natureza afetiva, que se manifesta pela rejeição dos homossexuais; e a dimensão cultural, de natureza cognitiva, em que o objeto da rejeição não é o homossexual enquanto indivíduo, mas a homossexualidade como fenômeno psicológico e social. Essa distinção permite compreender melhor uma situação bastante disseminada nas sociedades modernas que consiste em tolerar e, até mesmo, em simpatizar com os membros do grupo estigmatizado, no entanto, considera inaceitável qualquer política de igualdade a seu respeito.
}

Pensando essas questões e compreendendo que o ciberespaço tem sido lugar privilegiado para a inscrição polissêmica de dizeres e a inscrição de inúmeros dizeres e sentidos, nosso trabalho pretende propor reflexões acerca do modo como as tecnologias afetam as relações com o discursivo. O ciberespaço tem produzido interferências e modificações nas formas de relação entre os sujeitos e na própria organização de nossa sociedade, nos mais variados aspectos, áreas e costumes (CASTELLS, 2003; DIAS, 2011; DIAS; COELHO, 2014; GARCIA; SOUSA, 2014; WERTHEIM, 2001). Consideramos que o ciberespaço interfere no processo de relação e produção dos discursos e sentidos, sendo que trabalhos na AD também têm contribuído para pensar tais pontos (DIAS, 2011; GARCIA; SOUSA, 2014). 
Como mostram Garcia e Sousa (2014, p. 87):

\begin{abstract}
A rede produz, desse modo, novas formas de individuação dos sujeitos, abre para a multiplicidade dos sentidos, sustenta desavenças, conflitos. A rede é um espaço heterogêneo, sustentado por relações de poder, que permite ao sujeito do século XXI ler temas que o afetam, dizer fatos que o incomodam, viver a possibilidade de uma sociedade menos sexista, violenta. $\mathrm{O}$ ciberespaço permite a militância, permite a discussão de temas que afetam o funcionamento do espaço urbano. Na rede, confrontos surgem na tentativa de fundar outros discursos à sociedade, outras formas de socialização em que não só o sujeito homemheterossexual tenha voz, mas em que todos os sujeitos mulher, homossexual, bissexual, transexual possam dizer e não serem ditos por uma sociedade baseada em uma violência patriarcal de gênero que também circula na rede.
\end{abstract}

Nessa direção, o Facebook tem sido um espaço interessante de observação da inscrição de discursos, permitindo analisarmos como na contemporaneidade temos um espaço de discussão da homofobia inscrito por uma entidade do Governo Federal. Nessa página on-line, o dizer oficial é comentado, discutido, questionado, desmentido, replicado, marcando a possibilidade de outras inscrições que sejam iguais ou diferentes daquelas da página governamental, já que as filiações ideológicas que constituem o(s) dizer(es) de um governo sempre são passíveis de serem outras, visto que as relações com a memória e os sentidos também podem vir a serem outras. Selecionamos como corpus três postagens da página da SDH/PR que abordam a homofobia. Esses materiais foram publicados entre janeiro de 2013 e janeiro de 2015.

Ao ser objeto de discussão, a homofobia ganha destaque como fato, como algo que ocorre no cotidiano de muitos brasileiros e que o governo identifica como uma violência que deve ser combatida. Temos o jogo com sentidos sócio-historicamente inscritos, nos quais ser gay era algo identificado como um problema ou algo errado (crime, pecado, doença), temos a desestabilização desses sentidos e a filiação à produção de um dizer que coloca o problema não no fato de o sujeito ser identificado ou identificar-se como gay, mas na existência do preconceito e na violência no cotidiano. O problema está em ser homofóbico e praticar atos de homofobia; o estranhamento na inscrição do dizer do Estado está em sujeitos que se inscrevem nessa região de sentidos.

Trabalhar com o conceito de memória no campo da AD é refletir acerca de uma noção distante de uma compreensão psicologista. Nessa perspectiva, a memória não é uma estrutura plena e homogênea, passível de ser acessada e acumulada, em que determinados acontecimentos são inscritos e outros tantos não. A memória é marcada por rupturas, deslocamentos, regularizações e inversões; nesse sentido, sua constituição é polêmica. No trabalho de relação com os textos, o sujeito lida com implícitos, a memória está relacionada ao processo de repetição e regularidade, atrelado ao que é compreendido como evidente; desse modo, o sujeito lida com esse processo, relacionando-se com o que é compreendido como já-dado, impossível de não ser entendido (PÊCHEUX, 2010). É sempre possível ocorrer o rompimento, o deslizamento do que (a)parece sedimentado, o que produz a possibilidade de termos (sempre) o acontecimento discursivo, desregulando o que era posto como evidente. Na relação com a memória, o rompimento é sempre passível de ocorrência, gerando a tensão ao termos o acontecimento, rompendo com o que é posto como evidente, o que ajuda a compreendermos a não transparência do discurso. 
Observamos a tecnologia produzindo em seu processo de manuseio efeitos de potência, o imaginário de que tudo é passível de ser acessado, encontrado, escrito, inscrito, organizado e utilizado; como se não houvesse limites para o sujeito ao ser posto em contato (e complementado) pela máquina, já que, na esteira da produção desse efeito de superpotência, temos em jogo a compreensão da existência da superproteção. A naturalização desses efeitos implica modos de o sujeito estabelecer relações com os outros sujeitos e o próprio processo de forjar sua subjetividade. Destacamos que trabalhos anteriores da AD refletiram acerca da relação entre sujeito e ciberespaço (DIAS, 2011; DIAS; COELHO, 2014; GARCIA; SOUSA, 2014; ORLANDI, 2012). Importante pensar que o processo de produção do discurso no espaço do digital, ao compreendermos a inscrição de um dizer do governo sobre determinada questão, coloca em jogo outros gestos de dizer e de leitura. Identificamos que a mudança nas condições de produção resulta em outra produção de sentidos, de significados, de relações dos sujeitos com a exterioridade. Ao pensarmos o corpus trabalhado em nosso texto, observamos que sua produção é marcada não apenas pelo uso de caracteres referentes a esse universo, como o uso da hashtag "\#nãoguardenoarmário", mas também pela escolha de um espaço online para a inscrição de dizeres que são institucionais. O dizer inscrito e publicado por um órgão oficial não é apenas visto por quem se filia a essa página on-line, mas também pode receber o indicativo de que a postagem é de seu agrado, pela opção 'curtir', e compartilhado pelos sujeitos-navegadores em suas páginas pessoais.

Atentamos que o gesto de compartilhar algo na página pessoal resulta em marcas de filiação do sujeito e que colocam em outro modo de circulação aquele dizer institucional que passa a circular em novas condições e em contato com outros sujeitos, inscritos em posições discursivas outras. Filiar-se a dizeres difundidos pelo Governo Federal do Brasil, que possuem caráter favorável aos LGBT e contrários à discriminação resulta em gestos de filiação, pertencimento e que marcam relação com a forma com que o sujeito se identifica com sentidos acerca daquele assunto. A circulação e a produção de dizeres no ciberespaço colocam em jogo a relação com a memória, os processos de produção do discurso, escrita e leitura. O que é inscrito no espaço da rede eletrônica, por um órgão oficial, interfere na produção de uma memória, sobre a comunidade LGBT e sua relação com os sujeitos e o governo federal do Brasil. Para que as palavras façam sentido, é importante que tenham sido já-ditas, em outro(s) contexto(s), o que as coloca em jogo de outro modo; essa relação em espiral marca a produção dos discursos e sentidos na perspectiva da $\mathrm{AD}$.

Compreendemos que, ao discutir a noção de memória, pensando no corpus de nossa pesquisa, seja relevante retomar as considerações de Pêcheux (1997b) acerca da noção de ideologia. Para Pêcheux (1997b, p. 160), a ideologia não é ocultação da verdade, mas a relação com a produção do sentido, de modo que algo faça ou não sentido para o sujeito, em uma relação que permite a identificação de evidência em determinado enunciado. A ideologia afeta a constituição do sujeito e sua relação com a produção dos sentidos, por isso não compreendemos os sentidos como já dados ou colados às palavras, já que sempre são passíveis de serem outros, não havendo a seguridade do sentido na história, visto que ele sempre pode ser rompido e ser inscrito de outro modo. Salientamos que romper com o estabilizado, questionar o que parece evidente, marca a imprevisibilidade do sentido e sua constituição heterogênea. Partindo dessas considerações, trabalharemos na próxima seção com nosso material de análise. 
Começamos a pensar nosso corpus com o enunciado "não ligue para o que os outros pensam” da Figura 1, publicada em 2014 na página da SDH/PR.

\section{Figura 1 - Página da Secretaria de Direitos Humanos da Presidência da República}
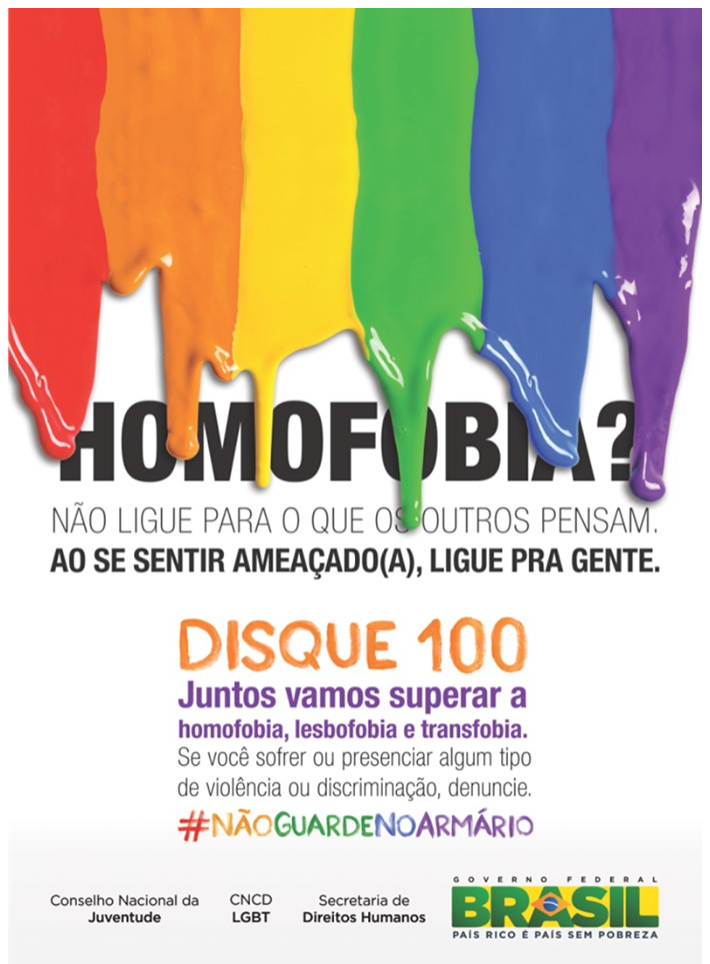

Fonte: Disponivel em: <https:/www.facebook.com/direitoshumanosbrasil/photos/pb.165500080198037.2207520000.1432157970./638380172910023/?type=3\&theater $>$. Acesso em: 10 ago. 2015.

Esse discurso marca a busca pela inscrição de sentidos nos quais o interesse é pelo rompimento do que coloca estar vinculado como parte da comunidade LGBT, como algo que não deve ser visto como um problema. Romper com essa compreensão é posto como aquilo que deve ocorrer, colocando a necessidade da inscrição de sentidos outros em jogo. Marcamos novamente que é interessante pensar o funcionamento desse outro gesto de inscrição, pelo qual não se deve dar ouvidos aos que marcam que ser homossexual é um problema, e isso ser dito e escrito pelo governo federal acreditamos produzir efeitos de deslocamento.

A postura do governo federal marca uma posição de defesa da comunidade LGBT. O Estado oferece espaços de denúncia contra o preconceito, inscrevendo-o em uma posição de ilegalidade, já que sua prática pode resultar em denúncias e ações legais por parte da esfera governamental na defesa da comunidade LGBT. Nos recortes "ao se sentir ameaçado(a), ligue pra gente", "se você sofrer ou presenciar algum tipo de violência ou discriminação, denuncie" e "disque 100" (Figura 1), temos o discurso oficial marcando uma linha voltada para receber denúncias de homofobia, indicando a preocupação do 
governo com essa forma de violência, não qualquer tipo de violência, mas uma que é motivada por um ódio específico. A posição do governo marca uma filiação à compreensão do risco que a homofobia produz no cotidiano dos sujeitos e a busca por evitar sua prática por meio de uma série de ações e no oferecimento de condições de participação da sociedade na luta contra o preconceito. Estar inscrito como sujeito que denuncia a violência é identificado como algo correto, visando à construção de uma sociedade mais justa. Nesse discurso, o estranhamento não está em não ser heterossexual, em ser identificado como membro da comunidade LGBT, mas sim em não estranhar, não questionar e não denunciar gestos de "violência ou discriminação" contra esses sujeitos.

Ao pensarmos a publicação desse dizer na página da $\mathrm{SDH} / \mathrm{PR}$, temos um posicionamento da Secretaria de Direitos Humanos e a compreensão de que esse assunto está relacionado aos interesses dessa área do governo, interessada no trabalho de promoção do bem-estar humano e na preservação de direitos básicos a todos, garantidos por leis nacionais e tratados internacionais, conforme detalhamos na seção anterior, marcando, assim, a relevância do espaço da diferença e da igualdade de direitos em sociedades democráticas (LIONÇO, 2008). Nos últimos anos, o governo brasileiro vem atuando no sentido de promover ações e políticas públicas de defesa dos direitos da população LGBT, com a busca por assegurar a não violação de seus direitos em variados campos, inclusive com a publicação de documentos oficiais e ações como a realizada na página da SDH/PR. Salientamos que a luta contra a homofobia é ponto fundamental no avanço de conquistas em outras áreas para a comunidade LGBT. De acordo com Lionço (2008), conquistas como a proposição de projetos de lei contrários ao preconceito, obtenção de direitos, como os referentes aos benefícios sociais, a criação de organizações de defesa dos LGBT e o espaço no mercado de consumo capitalista dos sujeitos filiados a esse movimento (inseridos como consumidores), têm contribuído para a produção de outros sentidos acerca dos sujeitos filiados à comunidade LGBT.

O traço do ciberespaço aparece na inscrição dos dizeres na rede eletrônica, no processo de divulgação da posição do governo federal do Brasil acerca da homofobia, como observamos nas Figuras 1 e 3 com o uso da hashtag "\#” (“\#nãoguardenoarmário") em que esse gesto inscreve esse dizer como filiado ao espaço da rede eletrônica. Como apontam Dias e Coelho (2014, p. 235), tecnicamente, a formulação das hashtags ocorre pela junção de uma palavra precedida por uma cerquilha (\#), que funciona como hiperlink de assuntos dentro da rede, indexados por meio dos mecanismos de busca, como o Google por exemplo: "Isso permite que outros usuários cliquem nas hashtags ou as busquem nos mecanismos de busca, para ter acesso a todas as mensagens, fotos e publicações que participaram da discussão de um tópico nas redes sociais" (DIAS; COELHO, 2014, p. 235). Discursivamente, as hashtags marcam um funcionamento. Nesse caso, a analogia com o armário não é aleatória, mas relacionada a uma memória, um já-lá que sustenta a relação entre essa palavra com o universo LGBT. Estar no armário é não inscrever sua sexualidade no espaço público por receio do preconceito, da não aceitação. Esse enunciado é ressignificado e passa a inscrever que é importante a denúncia, que ela não seja escondida por medo do que os outros vão pensar. Denunciar e lutar contra a homofobia é identificado aqui como algo positivo e que deve ser feito por todos, como parte de um combate que é histórico e que afeta toda a sociedade. 
Compreendemos a existência de particularidades no processo de inscrição e produção dos discursos e dos sentidos no ciberespaço. Temos deslocamentos que devem ser considerados no gesto de análise e leitura por parte do analista. Não temos uma mera mudança de suporte, mas de condições de acesso, leitura e produção dos discursos. Os efeitos de ressonância e relação com os discursos e sujeitos que acessam esses materiais são particulares, já que a velocidade e as condições de interação, principalmente no Facebook, estão atreladas a considerações de questões como velocidade, acesso, tempo e interatividade.

\section{Figura 2 - Página Secretaria de Direitos Humanos da Presidência da República}

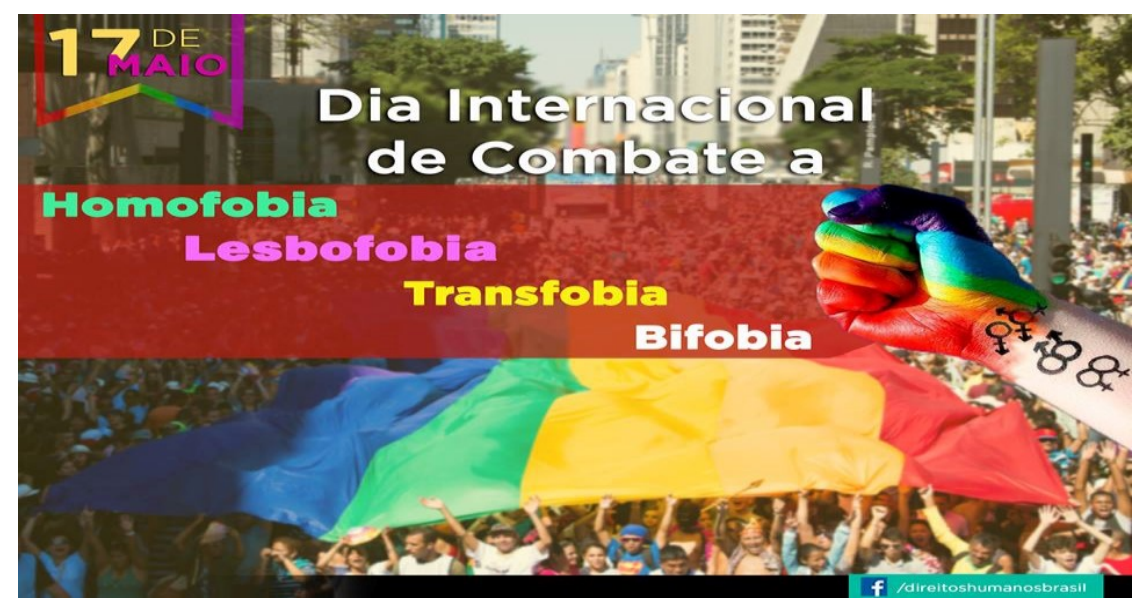

Fonte: Disponivel em: $<$ https://www.facebook.com/direitoshumanosbrasil/photos/pb.165500080198037.2207520000.1432157084./846801855401186/?type=3\&theater>. Acesso em: 10 ago. 2015.

\section{Figura 3 - Página Secretaria de Direitos Humanos da Presidência da República}

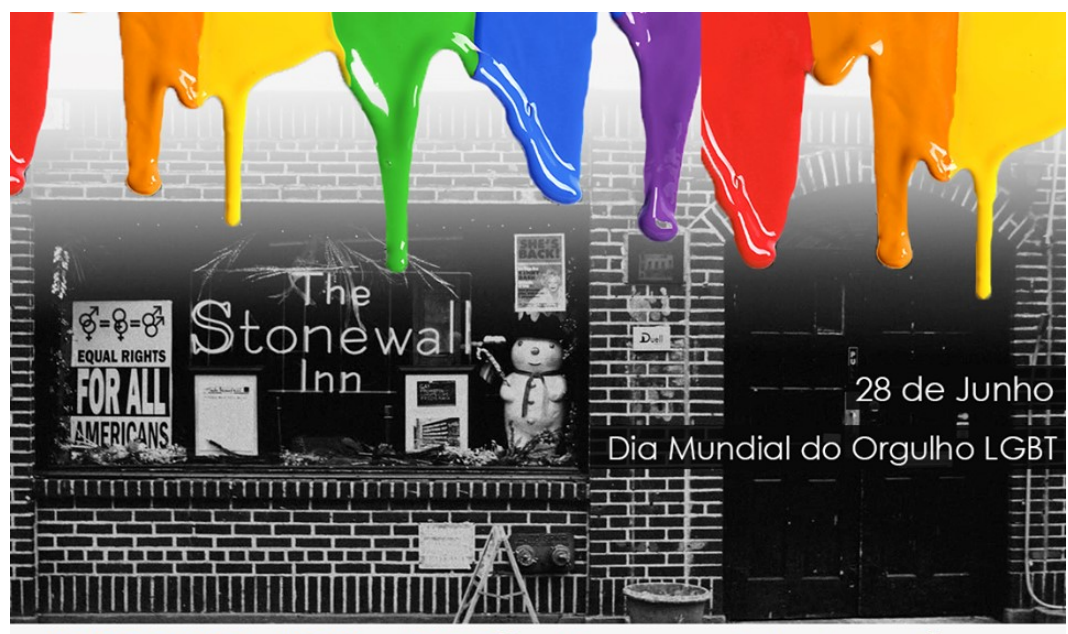

\section{DISQUE 100 \#NÃOGUARDENOARMÁRIO}

Fonte: Disponivel em: <https://www.facebook.com/direitoshumanosbrasil/photos/pb.165500080198037.2207520000.1432157588./669949099753130/?type=3\&theater>. Acesso em: 10 ago. 2015. 
O ciberespaço como local de inscrição de discursos de apoio à causa LGBT não está restrito à promoção da luta contra a homofobia (e também a "lesbofobia", "transfobia" e "bifobia"), mas também como espaço de inscrição de comemoração pela possibilidade de inscrever sentidos de luta, de combate ao preconceito, como marcados nas Figuras 2 e 3.

Na Figura 3, temos a retomada de uma memória, na qual um evento histórico é destacado para marcar esse sentido de comemoração. Esse fato considerado importante para a comunidade LGBT é o "Dia mundial do orgulho LGBT", comemorado no dia 28 de junho. Não é qualquer acontecimento que é retomado para marcar a luta contra o preconceito, mas a Revolta de Stonewall ${ }^{5}$, evento identificado como fundamental para a comunidade LGBT em sua relação com a sociedade, os poderes estatais, os sentidos de pertencimento e de necessidade de luta política. Gostaríamos de tomar a formulação "não guarde no armário" pelo que ela faz falar da memória sobre a homossexualidade, retomando fios já dados para enlaçá-los de outro modo. De um lado, temos a expressão bastante corriqueira de que "sair do armário" diz respeito ao fato de assumir-se como gay, o que implica efeitos de coragem para mostrar algo antes guardado a sete chaves, trancado como segredo. No caso desse enunciado, temos uma volta a mais em torno dessa memória, um retorno não do mesmo, mas do atualizado, tendo em vista que não se trata mais de sair do armário, mas de não guardar a violência dentro dele, ou seja, de denunciar os crimes sofridos pelos gays. Nesse movimento do já dito e do dizer atualizado pelas condições históricas, temos o movimento do discurso.

Ao pensarmos a produção desses discursos, observamos que eles não são produzidos de qualquer posição, e sim pelo governo federal brasileiro; isso tem um peso e deve ser considerado, já que a inscrição do discurso a partir de diferentes posições produz sentidos distintos. A construção de um gesto de compreensão sobre algo é afetado por uma série de pontos, como, por exemplo, determinado sujeito é autorizado ou não a inscrever determinado sentido. O dizer institucional tem um peso que deve ser considerado colocando em jogo sentidos vistos como autorizados, e atua silenciando outros tantos, identificando-os como inadequados ou ilegais. Acreditamos na relação dessa análise com o que Pêcheux (1997a, p. 58) destaca ao entender que a alguns é compreendido como natural que produzam interpretações, enquanto a outros é autorizada a reprodução desses gestos de leitura, enfatizando o que é defendido por esses sujeitos autorizados a produzir sentidos.

De acordo com Pêcheux (1997a, p. 60), o fator ideológico está envolvido na atuação das instituições e no seu processo de inscrição discursiva e no que resulta na produção de uma memória coletiva. A inscrição do governo federal no sentido de promover um discurso contra o preconceito coloca em jogo dizeres autorizados, os quais serão copiados, repetidos e anotados no gesto de leitura por parte de outros sujeitos, tendo sua importância na produção de dizeres e documentos institucionais, produzindo dizeres que

\footnotetext{
${ }^{5}$ Em 1969, ocorreu a Revolta de Stonewall, evento significativo para a luta contra a opressão e a homofobia. Esse acontecimento ocorreu nos Estados Unidos em decorrência da busca dos homossexuais por respeito e pelo fim da violência contra os grupos LGBT (SEDGWICK, 2007). Stonewall Inn é um bar em Nova York, o lugar e a data da Revolta (28 de junho) tornaram-se simbólicos na luta pelos direitos da população LGBT e para o enfrentamento do preconceito.
} 
serão tidos como referência, como saberes autorizados a circularem. Salientamos que os sujeitos inscritos em uma posição contrária a adotada pelo governo federal podem retomar tais discursos para marcar outras regiões de sentido e produzir interpretações diferentes, inclusive contrárias à postura do governo.

Compreendemos que a resistência está inscrita no jogo de luta dos homossexuais. Nas materialidades analisadas, temos o discurso de defesa de uma sexualidade que é heterogênea, no qual a heterossexualidade não é compreendida como automática pelo Estado. Nosso corpus permite identificarmos novas inscrições discursivas por parte do governo federal nas suas observações acerca dos sujeitos inscritos como parte do grupo LGBT. Alterações possíveis pelos deslocamentos com os quais os sentidos passam no decorrer da história e em sua relação com os sujeitos. Salientamos que esse processo de inscrição de outros sentidos sobre a homossexualidade coloca em jogo um espaço de disputa e tensão entre sujeitos, na relação entre aqueles que buscam não romper com sentidos negativos acerca da homossexualidade e do preconceito e dos que buscam inscrever outras possibilidades sobre a homossexualidade, o pertencimento ao movimento LGBT e a luta contra o preconceito. Essa disputa é constitutiva do discurso e da produção de sentidos e envolve o processo de produção das interpretações, conforme destaca Orlandi (2007, p. 40-42).

Pelo funcionamento da memória, observamos a não aleatoriedade envolvida na inscrição de discursos e na retomada de determinados sentidos. Retomar um evento mundial como a Revolta de Stonewall e não outros tantos possíveis, marca a identificação da importância desse acontecimento na história e sua força simbólica dentro das próprias relações de associação ao movimento LGBT e na luta contra a homofobia. Pensando a não aleatoriedade de retomadas de datas e eventos, consideramos a relevância de destacar o enunciado " 17 de maio" e " 28 de junho" para pensarmos como o já-dito se inscreve no discurso, constituindo enunciados possíveis de serem enunciados pela retomada do histórico e pela possibilidade de mover sentidos, de inscrevê-los em outros contextos e condições. A repetição, em outro contexto, dessas duas datas marca seu efeito, sua ressonância na estrutura da memória discursiva.

Remeter a 17 de maio não é aleatório. É a data na qual é comemorado o dia em que a homossexualidade foi retirada da categoria "doença" da Classificação Internacional de Doenças (CID), algo que permitiu outros espaços de inscrição para esses sujeitos e os discursos sobre ser homossexual. Atentamos a posição da instituição que inscreveu um outro gesto de interpretação sobre a homossexualidade, no caso, a Organização Mundial de Saúde (OMS) em 1990 (GRUPO GAY DA BAHIA, 2015). Destacamos novamente a questão de Pêcheux (1997a, p. 58) referente a quem está autorizado a produzir ou não interpretações, no caso, a adoção da data foi motivada por uma decisão política da OMS que produziu impacto na produção de sentidos pelos e sobre os sujeitos-homossexuais. A Revolta de Stonewall ocorreu na data de 28 de julho e foi tão significativa que é nela que é comemorado anualmente o "Dia Mundial do Orgulho LGBT". Não temos a aleatoriedade, mas sim, a retomada de um enunciado que é interpretado como em relação a esse universo de significação, a uma memória de um grupo. Identifica-se a data como relevante e seu uso será compreendido por quem fizer parte ou tiver acesso aos acontecimentos considerados importantes ao movimento LGBT (SEDGWICK, 2007). A 
inscrição das marcas compreendidas como relevantes ao movimento LGBT procura assegurar a interpretação, a pretensa garantia da relação dos sujeitos-navegadores que acessam a página do Facebook aqui analisada com determinados sentidos.

Consideramos que a inscrição da marca "combate" (Figura 2) coloca em jogo a historicidade, os efeitos de embate que permeiam a produção de dizeres acerca dos que se inscrevem dentro das relações da comunidade LGBT, dentro desse espaço de identificação. Combate que ainda está sendo vivenciado, em jogo nas tramas dos discursos, como podemos observar na Figura 2. O combate é comemorado, existe uma data para que seja lembrado, o que inscreve essa data e esse fato como dignos de serem pensados e considerados como relevantes - o que não pode ser esquecido e deve produzir efeitos em dizeres oficiais de nosso país, o que é considerado digno de circular na materialidade on-line de uma Secretária de Estado do Brasil. A institucionalização de determinadas datas como dias a serem lembrados, como passíveis de serem comemorados marcam os efeitos do político no histórico e desvelam a não aleatoriedade desse processo. Datas para combater, comemorar e orgulhar-se das diferenças são apresentadas, inscritas no discurso oficial, como observado nas Figuras 2 e 3, retomando a continuidade de uma relação dos sujeitos com a memória e sua construção no cotidiano dos brasileiros.

\section{CONSIDERAÇÕES FINAIS}

A produção de discursos no ciberespaço merece atenção e reflexões no campo da AD, principalmente os que envolvem discursos produzidos pelas mais variadas instâncias governamentais. Nosso interesse de análise objetivou discutir a produção de discursos por parte do governo brasileiro acerca de uma violência praticada contra determinados sujeitos, analisando a produção e circulação de enunciados no Facebook, considerando a ideologia e a memória discursiva sustentando esses processos, mas também marcando mudanças na produção de sentidos sobre a questão da homossexualidade e como a discriminação contra esses sujeitos é objeto de interesse e preocupação da SDH/PR nos últimos anos (2013-2015).

No trabalho desenvolvido, procuramos pensar os discursos sobre a homofobia em sua circulação, constituição e difusão, considerando o ciberespaço como local de promoção de debates, entendendo que a discussão de fatos do cotidiano tem sido intensificada nos últimos anos, com o aumento das possibilidades de acesso e uso dessas redes (CASTELLS, 2003). Salientamos que redes sociais, como o Facebook, são espaços privilegiados de interação e discursividade dos sujeitos na contemporaneidade.

Acreditamos que o uso desse espaço por parte das estruturas governamentais deve crescer nos próximos anos e permitir mais possibilidades de análises acerca dos efeitos produzidos por tais gestos de inscrição no cotidiano dos sujeitos, a observação dos efeitos de produção de tais discursos no ciberespaço e como estão em relação aspectos on e offline, inclusive os que envolvem discussões sobre homofobia e os sujeitos da comunidade LGBT. 
BARROS NETO, N. Um homossexual é morto a cada 26h no Brasil, diz grupo gay. Folha de S.Paulo, São Paulo, 10 jan. 2013. Disponível em: <http://www1.folha.uol.com.br/cotidiano/1212866-um-homossexuale-morto-a-cada-26h-no-brasil-diz-grupo-gay.shtml>. Acesso em: 15 ago. 2015.

BORRILlO, D. Homofobia: história e crítica de um preconceito. Belo Horizonte: Autêntica, 2010.

BRASIL. Decreto n. 8.162, de 18 de dezembro de 2013. Aprova a Estrutura Regimental e o Quadro Demonstrativo dos Cargos em Comissão e das Funções de Confiança da Secretaria de Direitos Humanos da Presidência da República e remaneja cargos em comissão. Diário Oficial da União, Brasília, DF, 18 dez. 2013. Seção 1, p. 47-52. Disponível em: <http://www.planalto.gov.br/ccivil_03/_Ato20112014/2013/Decreto/D8162.htm>. Acesso em: 10 set. 2015.

. Secretaria de Direitos Humanos da Presidência da República. LGBT. Brasília, 2015. Disponível em: <http://www.sdh.gov.br/assuntos/lgbt>. Acesso em: 15 ago. 2015.

CASTELLS, M. A galáxia da Internet: reflexões sobre a Internet, os negócios e a sociedade. Rio de Janeiro: Jorge Zahar, 2003.

DIAS, C. P. Cidade, cultura e corpo: a velocidade do mundo. Campinas: UNICAMP, 2011.

DIAS, C. P.; COELHO, A. V de Vinagre: a produção de imagens humorísticas sobre as manifestações brasileiras de 2013 nas redes sociais. In: PATTI, A. R. et al. (Org.). Textecendo discursos na contemporaneidade. São Carlos: Pedro \& João Editores, 2014. p. 235-251.

GARCIA, D. A.; SOUSA, L. M. A. Ler o arquivo hoje: a sociedade em rede e suas andanças no ciberespaço. Porto Alegre, Revista Conexão Letras, v. 9, n. 11, p. 83-97, 2014. Disponível em: $<$ http://seer.ufrgs.br/index.php/conexaoletras/article/view/55143>. Acesso em: 01 ago. 2015.

GRUPO GAY DA BAHIA. 17 de maio internacional de combate a homofobia. Disponível em: $<$ http://grupogaydabahia.com.br/2015/05/19/17-de-maio-internacional-de-combate-a-homofobia/ >. Acesso em: 20 ago. 2015.

LIONÇO, T. Que direito à saúde para a população GLBT? Considerando direitos humanos, sexuais e reprodutivos em busca da integralidade e da eqüidade. Saúde e Sociedade, São Paulo, v. 17, n. 2, p. 11, 21, 2008. Disponível em: <http://www.scielo.br/scielo.php?pid=S0104-

$12902008000200003 \&$ script $=$ sci_arttext $>$. Acesso em: 15 ago. 2015.

MELLO, L.; BRITO, W.; MAROJA, D. Políticas públicas para a população LGBT no Brasil: notas sobre alcances e possibilidades. Cadernos Pagu, Campinas, v. 39, p. 403-429, jul./dez. 2012. Disponível em: $<$ http://www.scielo.br/scielo.php?pid=S0104-83332012000200014\&script=sci_arttext $>$. Acesso em: 15 ago. 2015.

MOTT, L. A revolução homossexual: o poder de um mito. Revista USP, São Paulo, n. 49, p. 40-59, mar./maio 2001. Disponível em: <http://www.usp.br/revistausp/49/04-luizmott.pdf $>$. Acesso em: 21 ago. 2011.

ORLANDI, E. P. Análise de discurso: princípios e procedimentos. 7. ed. Campinas: Pontes, 2007.

Apagamento do político na ciência: notas à história da análise de discurso-fragmentação, diluição, indistinção de sentidos e revisionismo. In: ideologia. 2. ed. Campinas: Pontes Editores, 2012. p. 13-36.

PÊCHEUX, M. Ler o arquivo hoje. In: ORLANDI, E. P. (Org.). Gestos de leitura: da história no discurso. 2. ed. Campinas: Editora da Unicamp, 1997a. p. 55-66. $1997 \mathrm{~b}$.

Semântica e discurso: uma crítica à afirmação do óbvio. 3. ed. Campinas: Editora da UNICAMP,

Papel da memória. In: ACHARD, P. et al. (Org.). Papel da memória. 3. ed. Campinas: Pontes Editores, 2010. p. 49-57.

SEDGWICK, E. K. A epistemologia do armário. Cadernos Pagu, Campinas, v. 28, p. 19-54, 2007. Disponível em: <http://www.scielo.br/pdf/cpa/n28/03.pdf>. Acesso em: 11 ago. 2015.

SOARES, A. S. F. A homossexualidade e a AIDS no imaginário de revistas semanais (1985-1990). 2006. 235 f. Tese (Doutorado em Linguística) - Universidade Federal Fluminense, Niterói, 2006.

Sujeito em discurso: sobre a homossexualidade na mídia (2005-2010). In: ROMÃO, L. M. S.; GALLI, F. C. S. (Org.). Conceitos discursivos em rede. São Carlos: Pedro \& João, 2012. p. 71-86. WERTHEIM, M. Uma história do espaço: de Dante à Internet. Rio de Janeiro: Jorge Zahar, 2001.

BASTOS, Gustavo Grandini; GARCIA, Dantielli Assumpção; SOUSA, Lucília Maria Abrahão e. A homofobia em discurso: direitos humanos em circulação. Linguagem em (Dis)curso - LemD, Tubarão, SC, v. 17, n. 1, p. 1124, jan./abr. 2017. 
Recebido em: 28/05/16. Aprovado em: 25/11/16.

Title: Homophobia in discourse: Human Rights in circulation

Authors: Gustavo Grandini Bastos; Dantielli Assumpção Garcia; Lucília Maria Abrahão e Sousa

Abstract: In accordance with the perspective proposed by the theoretical framework of French Discourse Analysis, this article aims at reflecting upon the constitution of meanings on the subject of homophobia on Secretaria de Direitos Humanos da Presidencia da República (SDH/PR) Direitos Humanos Brasil Facebook page, emphasizing the notions of ideology and discursive memory. The analysis focuses not only on the understanding of the effects of meaning produced in the sayings about homophobia published on this official web page of the government, but also on how the state adopts a certain position when engraving meanings on homophobia and human rights.

Keywords: Discourse Analysis. Facebook. Human Rights. Homophobia.

Título: La homofobia en discurso: Derechos Humanos en circulación

Autores: Gustavo Grandini Bastos; Dantielli Assumpção Garcia; Lucília Maria Abrahão e Sousa

Resumen: Anclado en la contribución teórica del Análisis del Discurso de línea francesa, este artículo tiene por objetivo reflejar sobre la constitución de sentidos en el tema homofobia en la página del Facebook de la Secretaria de Derechos Humanos de la Presidencia de la República (SDH/PR) Direitos Humanos Brasil, de enero de 2013 hasta enero de 2015, despegando las nociones de ideología y memoria discursiva en el trabajo de análisis. El análisis tiene foco en la comprensión sobre los efectos producidos en la inscripción de dichos acerca da homofobia divulgados en esa página electrónica oficial del gobierno, y cómo el Estado adopta cierta posición al inscribir sentidos acerca de un asunto.

Palabras-clave: Análisis del Discurso. Facebook. Derechos Humanos. Homofobia.

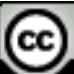

Este texto está licenciado com uma Licença Creative Commons Atribuição 4.0 Internacional.

BASTOS, Gustavo Grandini; GARCIA, Dantielli Assumpção; SOUSA, Lucília Maria Abrahão e. A homofobia em discurso: direitos humanos em circulação. Linguagem em (Dis)curso - LemD, Tubarão, SC, v. 17, n. 1, p. 1124, jan./abr. 2017. 